\title{
2-ETHYL-5-(3-INDOLYL)OXAZOLE FROM \\ STREPTOMYCES CINNAMOMEUS DISCOVERED BY CHEMICAL SCREENING \\ CHARACTERIZATION AND STRUCTURE ELUCIDATION \\ BY X-RAY ANALYSIS
}

\author{
Mathias Noltemeyer and George M. Sheldrick \\ Anorganisch-Chemisches Institut der Universität, \\ Tammannstr. 4, D-3400 Göttingen, F. R. G. \\ Hans-Ullrich Hoppe and Axel Zeeck* \\ Organisch-Chemisches Institut der Universität, \\ Tammannstr. 2, D-3400 Göttingen, F. R. G. \\ (Received for publication February 12, 1982)
}

\begin{abstract}
In the lipophilic extracts from Streptomyces cinnamomeus 2-ethyl-5-(3-indolyl)oxazole (1a) was detected by chemical screening methods. The structure of the crystalline 1a was determined by spectroscopic and X-ray analysis. The new mono- and dibromo derivatives $\mathbf{1 b}$ and $\mathbf{1 c}$ are described. 1a is identical with pimprinethine and belongs to a group of microbial indole alkaloids, which can be regarded as masked tryptamine derivatives.
\end{abstract}

An example of the diversity of Streptomyces metabolism is the observation that individual strains produce different secondary metabolites at the same time. If these metabolites differ fundamentally in structural type and activity spectrum, then there is a risk even with known strains of overlooking other types of natural products by one-sided screening.

Secondary metabolites produced under specified culture conditions in appropriate quantity can only be recognized with relative certainty when the thin-layer chromatograms of the various isolated raw products are stained with appropriate reagent sprays. Special staining reagents offer the possibility of identifying chosen classes of compounds ${ }^{1 \sim \sigma)}$. By a combination of several reagents which show a broad response to common substance classes, one may obtain an overall picture of the pattern of products from a single strain. In the chemical screening procedures the biological activity of the secondary metabolites is not immediately taken into account.

The antibiotic kirrothricin ${ }^{7,8)}$ constitutes the major component of the lipophilic raw product extracted from the culture filtrate of Streptomyces cinnamomeus (strain Tü 89). As byproducts were identified aureothin ${ }^{9)}$ and a weak base, which extinguished in UV-light on silica gel $\mathrm{F}_{254}$, turned blue-green in the Barrollier-test ${ }^{10)}$ and red-violet with EHRLICH's reagent. We describe below the characteristics and the bromination of this compound, together with a crystal structure analysis, which identified it as 2ethyl-5-(3-indolyl)oxazole (1a).

\section{Physico-chemical Characterization}

1a was separated by preparative layer chromatography on silica gel with chloroform - methanol (9: 1) out of the leading zone obtained on isolation of kirrothricin, and purified by recrystallization from

\footnotetext{
* To whom communications should be addressed.
} 
Fig. 1. IR spectrum of $\mathbf{1 a}$ in $\mathrm{KBr}$.

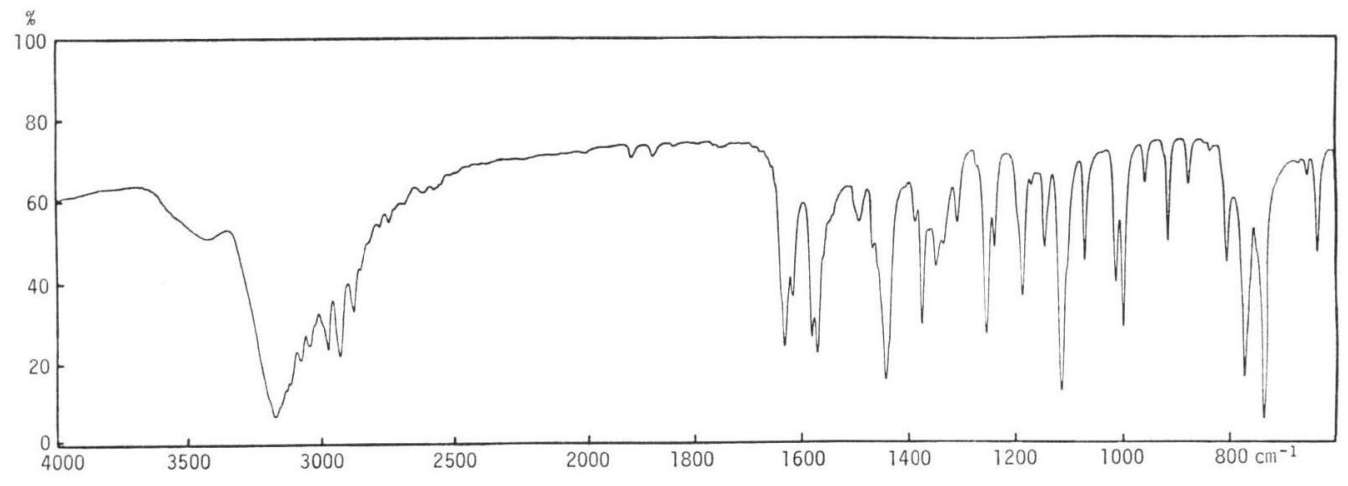

Fig. 2. PMR spectrum of $\mathbf{1 a}$ in $\mathrm{CDCl}_{3}$ (200 MHz, region of aromatic protons).

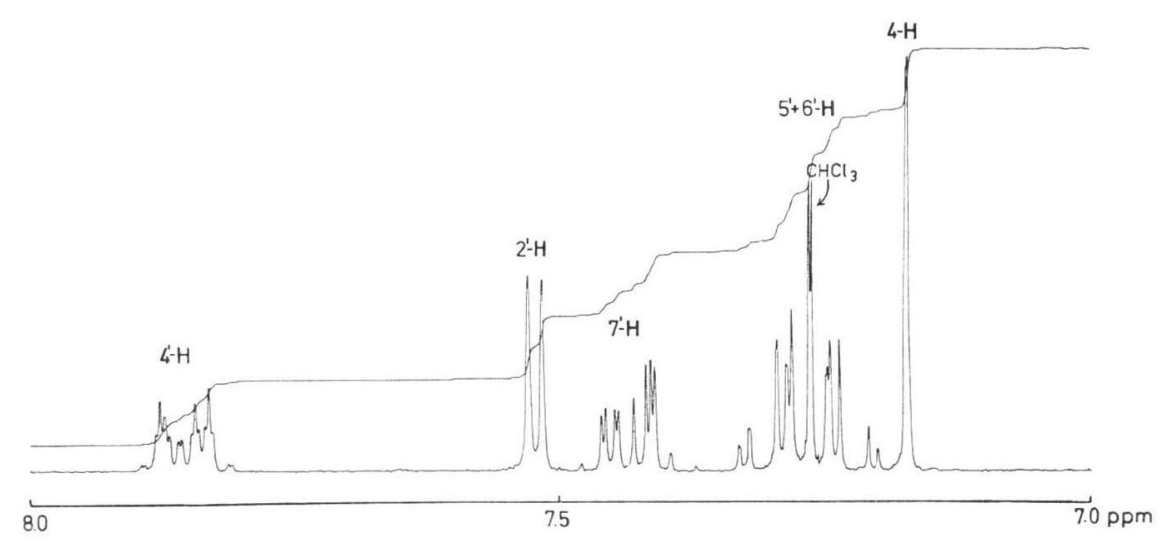

chloroform. The elementary analysis and mass spectrum prove the formula $\mathrm{C}_{13} \mathrm{H}_{12} \mathrm{~N}_{2} \mathrm{O}$ (M. W. 212) for the colorless, optically inactive 1a. The IR spectrum (Fig. 1) shows no intense absorption in the carbonyl region. The UV spectrum is identical in neutral and basic environments. The band at long wavelength exhibits a bathochromic shift with modified extinction coefficient in acids.

The PMR spectrum (Table 1) shows, in addition to an ethyl group, resonances for six aromatic $\mathrm{H}$ and one $\mathrm{NH}$. The $\delta$ values and assumed coupling constants of the aromatic protons, when input to a LAOCOON simulation (LAME, Varian), yielded a pattern which agreed very well with the observed spectrum (Fig. 2). Noteworthy is the deshielding $(\Delta \delta=0.18 \sim 0.32$ $\mathrm{ppm}$ ) compared with indole of all protons
Table 1. PMR data of 2-ethyl-5-(3-indolyl)oxazole (1a) in $\mathrm{CDCl}_{3}$ ( $\delta$ values in ppm).

\begin{tabular}{ccc}
\hline Position & PMR (200 MHz) & $\begin{array}{c}\text { CMR } \\
(25.2 \mathrm{MHz})\end{array}$ \\
\hline 2 & - & $164.6 \mathrm{~s}$ \\
4 & $7.18 \mathrm{~s}$ & $\left.123.4 \mathrm{~d}^{\mathrm{b}}\right)$ \\
5 & $2.90 \mathrm{q}(J=7.5 \mathrm{~Hz})$ & $149.5 \mathrm{~s}$ \\
6 & $1.43 \mathrm{t}$ & $11.5 \mathrm{q}$ \\
7 & $8.83($ broad $)$ & - \\
$1^{\prime}-\mathrm{NH}$ & $7.52 \mathrm{~d}(J=2.6 \mathrm{~Hz})$ & $123.1 \mathrm{~d}$ \\
$2^{\prime}$ & - & $105.0 \mathrm{~s}$ \\
$3^{\prime}$ & - & $125.0 \mathrm{~s}$ \\
$3^{\prime} \mathrm{A}$ & $7.85 \mathrm{~m} \mathrm{~m}^{\mathrm{a}}$ & $120.1 \mathrm{~d}$ \\
$4^{\prime}$ & $7.25 \mathrm{~m}$ & $118.1 \mathrm{~d}$ \\
$5^{\prime}$ & $7.29 \mathrm{~m}$ & $121.0 \mathrm{~d}$ \\
$6^{\prime}$ & $7.44 \mathrm{~m}$ & $112.5 \mathrm{~d}$ \\
$7^{\prime}$ & - & $137.8 \mathrm{~s}$ \\
\hline
\end{tabular}

a) Coupling constants in $\mathrm{Hz}$ derived from the LAOCOON simulation: $4^{\prime} / 5^{\prime}=7.8 ; 4^{\prime} / 6^{\prime}=1.3$; $4^{\prime} / 7^{\prime}=0.9 ; 5^{\prime} / 6^{\prime}=7.1 ; 5^{\prime} / 7^{\prime}=0.9 ; \quad 6^{\prime} / 7^{\prime}=8.1 ;$ $4^{\prime} / 1^{\prime}-\mathrm{NH}=0.8$.

b) The assignment of all doublets is not quite certain. 
except $7^{\prime}$-H. Double resonance experiments on 1a show an intramolecular nuclear Overhauser effect (NOE) of nearly $20 \%$ between $4-\mathrm{H}$ and $4^{\prime}-\mathrm{H}$, while there is no NOE enhancement to be seen for $2^{\prime}-\mathrm{H}$. By correlation of this NOE with the internuclear distance of the protons $4-\mathrm{H} / 4^{\prime}-\mathrm{H}$ we calculate $^{11)} 2.53 \AA$, whereas the same distance derived from X-ray data is $2.28 \AA$ (assuming $\mathrm{C}-\mathrm{H}=1.08 \AA$ ).

We conclude that the $S$-cis conformation shown in formula $\mathbf{1 a}$ and found in the crystal is also adopted in solution, but with appreciable torsional motion about $\mathrm{C}\left(3^{\prime}\right)-\mathrm{C}(5)$. The CMR spectrum (Table 1) is consistent with the structure 1a. The resonances are assigned in comparison with tryptamine $^{12)}$.

Bromination of 1a with elementary bromine in chloroform in the presence of iron, or with 2,4,4,6tetrabromocyclohexa-2,5-dienone ${ }^{13)}$ in chloroform, yielded the bromine derivatives $\mathbf{1 b}$ and $\mathbf{1 c}$, for which the structures could be derived primarily from the PMR data. As would be expected, the oxazole ring is brominated before the indole ring.

\section{X-Ray Analysis}

Single crystals of 2-ethyl-5-(3-indolyl)oxazole (1a) in the form of colorless plates were obtained by slow cooling of warm saturated chloroform solutions. The crystals are monoclinic $P 2_{1} / n, Z=4, a=$ 11.592 (15), $b=7.098$ (10), $c=13.257$ (18) $\AA, \beta=90.58(10)^{\circ}, \mathrm{U}=1090.7 \AA^{3}$. The structure was solved by multisolution tangent refinement. The assignment of the nitrogen and oxygen atoms, and the location of the hydrogen atoms, proved possible from the X-ray data alone. Fig. 3 shows a difference electron density synthesis calculated in the least-square plane passing through the non-hydrogen atoms. For the purposes of the preceding refinement in which the high-angle data were given increased weight, $\mathrm{O}(1)$ and $\mathrm{N}(3)$ were given nitrogen scattering factors and $\mathrm{N}\left(1^{\prime}\right)$ was input as carbon. The electron density map clearly shows all the hydrogen atoms which lie in the plane, together with excess electron density

Fig. 3. Difference electron density in the molecular plane based on a high-angle refinement of the heavy atoms.

All atoms were considered to be carbon in this refinement except for $N(3)$ and $O(1)$ which were given nitrogen scattering-factors. The hydrogen atoms and excess electron density at $\mathrm{N}\left(1^{\prime}\right)$ and $\mathrm{O}(1)$ (indicating that their scattering-factors should be increased by one electron) can be seen clearly.

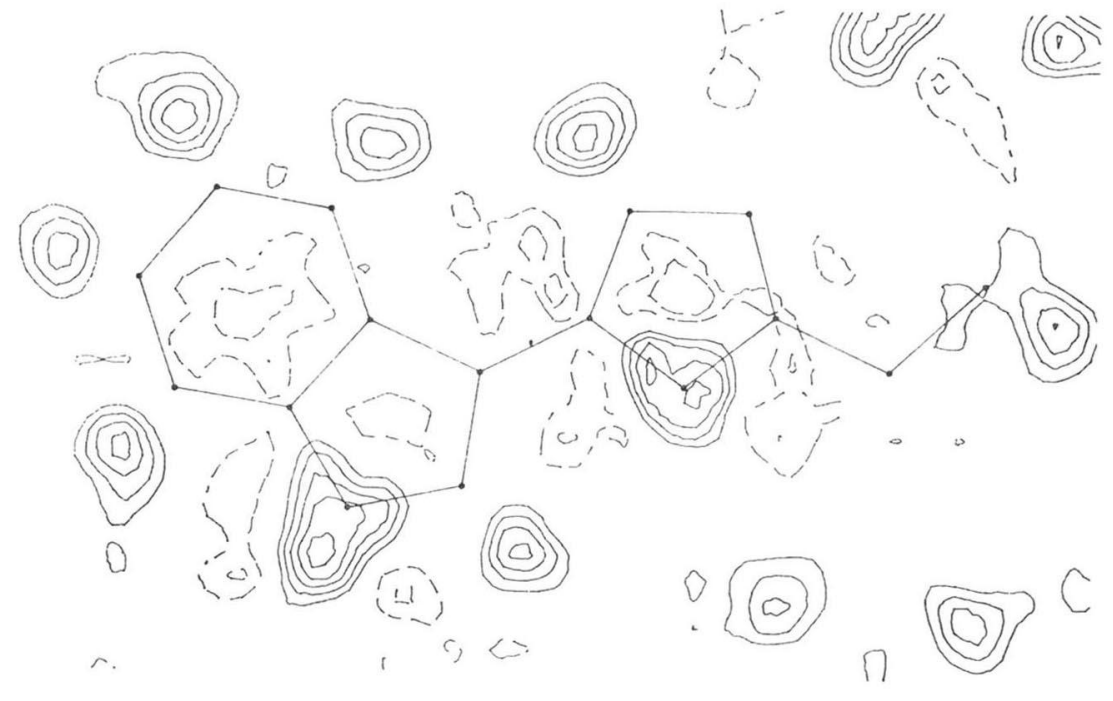


Fig. 4. The molecule of 1a, showing bond lengths (with standard deviations) in $\AA$.

Bond angles in degrees are: O1-C2-N3 113.2(2), O1-C2-C6 116.5 (2), C2-N3-C4 105.0 (2), N3-C4-C5 109.5 (2), N3-C2-C6 130.2 (2), C2-C6-C7 112.5 (2), O1-C5-C4 106.7 (2), O1-C5-C3' 116.7 (2), C4-C5-C3' 136.5 (2), C5-C3'-C2' 125.3 (2), C5-C3'-C3'A 127.8 (2), C2'-C3'-C3'A 106.9 (2), N1'-C2'-C3' 109.8(2), C2'-N1'-C7'A 109.3(2), N1'-C7'A-C7'130.3 (2), N1'-C7'A-C3'A 107.8 (2), C3'-C3'A-C7'A 106.1 (2), C3'-C3'A-C4'135.2 (2), C3'A-C4'-C5' 119.1 (2), C4'-C5'-C6' 121.3 (3), C5'-C6'-C7' 121.2 (2), C6'-C7'-C7'A 117.9 (2), C7'-C7'A-C3'A 121.8 (2), C2-O1-C5 105.5 (2), and $\mathrm{C}^{\prime} \mathrm{A}-\mathrm{C} 3^{\prime} \mathrm{A}-\mathrm{C} 4^{\prime} 118.7$ (2).

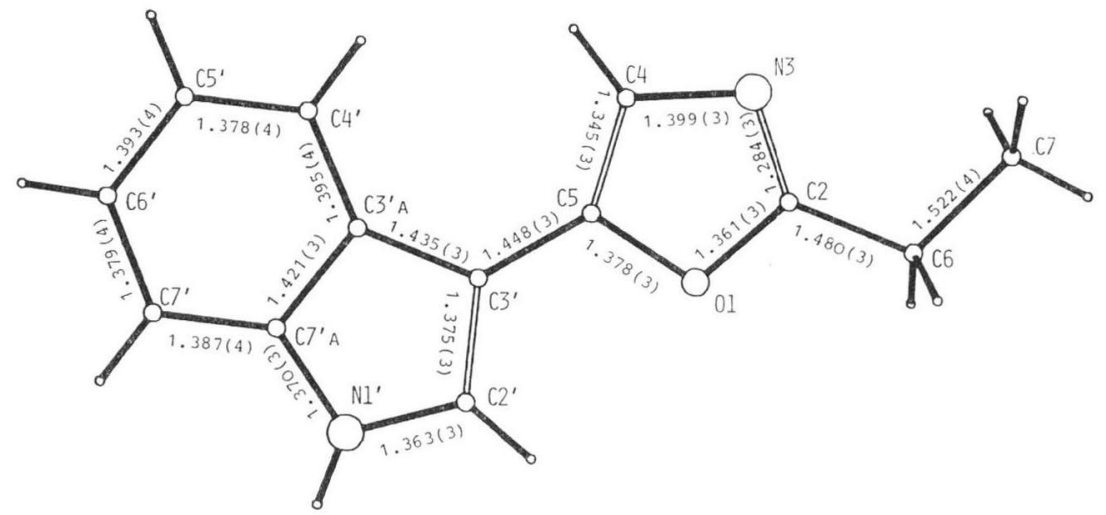

Table 2. Atomic coordinates (estimated standard deviations in parentheses) for nonhydrogen atoms.

\begin{tabular}{l|rcc}
\hline \multicolumn{1}{c|}{ Atom } & \multicolumn{1}{c}{$x$} & $y$ & $z$ \\
\hline $\mathrm{O}(1)$ & $0.0052(1)$ & $0.2327(3)$ & $0.5717(1)$ \\
$\mathrm{C}(2)$ & $0.0740(2)$ & $0.2267(4)$ & $0.6555(1)$ \\
$\mathrm{N}(3)$ & $0.1808(2)$ & $0.2564(4)$ & $0.6366(1)$ \\
$\mathrm{C}(4)$ & $0.1849(2)$ & $0.2856(4)$ & $0.5323(2)$ \\
$\mathrm{C}(5)$ & $0.0779(2)$ & $0.2715(4)$ & $0.4928(1)$ \\
$\mathrm{C}(6)$ & $0.0162(2)$ & $0.1873(4)$ & $0.7523(2)$ \\
$\mathrm{C}(7)$ & $0.1001(3)$ & $0.1852(5)$ & $0.8413(2)$ \\
$\mathrm{N}\left(1^{\prime}\right)$ & $-0.1078(2)$ & $0.2707(4)$ & $0.2702(1)$ \\
$\mathrm{C}\left(2^{\prime}\right)$ & $-0.0888(2)$ & $0.2518(5)$ & $0.3713(1)$ \\
$\mathrm{C}\left(3^{\prime}\right)$ & $0.0256(2)$ & $0.2841(3)$ & $0.3934(1)$ \\
$\mathrm{C}\left(3^{\prime} \mathrm{A}\right)$ & $0.0812(2)$ & $0.3258(3)$ & $0.2998(2)$ \\
$\mathrm{C}\left(4^{\prime}\right)$ & $0.1931(2)$ & $0.3723(4)$ & $0.2714(2)$ \\
$\mathrm{C}\left(5^{\prime}\right)$ & $0.2161(2)$ & $0.4020(5)$ & $0.1709(2)$ \\
$\mathrm{C}\left(6^{\prime}\right)$ & $0.1298(2)$ & $0.3872(4)$ & $0.0975(2)$ \\
$\mathrm{C}\left(7^{\prime}\right)$ & $0.0180(2)$ & $0.3426(4)$ & $0.1228(2)$ \\
$\mathrm{C}\left(7^{\prime} \mathrm{A}\right)$ & $-0.0059(2)$ & $0.3135(4)$ & $0.2239(2)$ \\
\hline
\end{tabular}

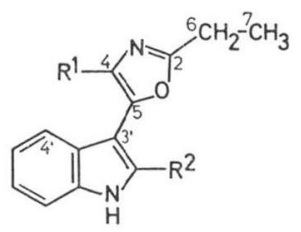<smiles>[R]c1ncc(-c2c[nH]c3ccccc23)o1</smiles>

1a $\mathrm{R}^{1}=\mathrm{R}^{2}=\mathrm{H}$

1b $\mathrm{R}^{1}=\mathrm{Br} ; \mathrm{R}^{2}=\mathrm{H}$

1c $\mathrm{R}^{1}=\mathrm{R}^{2}=\mathrm{Br}$

2a $\quad \mathrm{R}=\mathrm{CH}_{3}$

2b $\mathrm{R}=\mathrm{CH}_{2}-\mathrm{C}_{6} \mathrm{H}_{5}$

at $\mathrm{N}\left(1^{\prime}\right)$ and $\mathrm{O}(1)$, enabling these atoms to be assigned to nitrogen and oxygen respectively. The assignment was confirmed by the observed bond lengths. Refinement with individual isotropic temperature factors, a rigid methyl group, a riding model $(\mathrm{C}-\mathrm{H}=0.96 \AA)$ for the remaining hydrogen atoms, and the other atoms anisotropic, converged to $R=0.064$ for 1730 unique data with

$F>4 \sigma(F)$. Final atomic coordinates are presented in Table 2; Fig. 4 shows a view of the molecule.

\section{Discussion}

1a is identical to pimprinethine, which was isolated recently from Streptoverticillium olivoreticuli ${ }^{14}$ ) and structurally elucidated by synthesis ${ }^{14,15)}$. 1a is related to pimprinine (2a), which is produced by Streptomyces pimprina ${ }^{16)}$. Pimprinine shows antiepileptic ${ }^{17}$ ) and monoamine oxidase inhibitory activities $^{18)}$, both of which we expect for 1 a too. The 5-(3-indolyl)oxazoles can be looked upon as masked 
tryptamines. The X-ray analysis and PMR data indicate that the $S$-cis conformation of the coplanar ring systems is favoured. The distance of N(3) to N(1') in the conformer 1a is 5.872 (4) $\AA$ and is certainly important for the pharmacological effect. An antibacterial or antifungal activity for $1 \mathrm{a}$ and its bromine derivatives could not be proved.

1a, $2 \mathbf{a}$ and pimprineaphine (2b) $)^{14)}$ are microbial indole alkaloids and apparently more common than assumed until now. The compounds illustrate that it is difficult to detect all interesting secondary metabolites of a Streptomyces strain with the help of biological screening methods alone. Chemical screening methods are simpler, and after isolation and structure elucidation new metabolites can be subject to selected biological tests.

\section{Experimental}

General

IR spectra in pressed KBr disks were recorded using a Perkin Elmer model 297 spectrometer, UV spectra using a Zeiss DMR 21 spectrometer. PMR spectra were determined at $200 \mathrm{MHz}$ with a Varian XL-200, the FT-CMR spectrum at $25.2 \mathrm{MHz}$ on a Varian XL-100. Chemical shifts ( $\delta$ in ppm) are reported relative to internal TMS. EI-mass spectra were obtained on a Varian MAT 731 instrument $(70 \mathrm{eV})$ using the direct probe insert, high resolution with perfluorokerosine as a standard. All molecular formulae were in agreement with the high resolution data. Melting points were established on a heated microscope (Reichert, Austria) and were corrected. Thin-layer chromatography (TLC) was performed on silica gel plates (Merck $60 \mathrm{~F}_{254}$ ), preparative TLC on silica gel (Macherey \& Nagel, P UV 254 , plates $20 \times 40 \mathrm{~cm}$, layer $2 \mathrm{~mm}$ ). The X-ray analysis was carried out with $\mathrm{MoK} \alpha$ radiation on a Stoe two-circle diffractometer (layers $h 0-7 l$ ). 2916 unique reflexions were measured. All calculations were performed with programs written by G.M.S. for the Data General Eclipse mini-computer. Tables of thermal parameters, hydrogen atom coordinates and observed and calculated structure factors are available on request from the authors.

\section{Isolation of 2-Ethyl-5-(3-indolyl)oxazole (1a)}

Purification of $3.1 \mathrm{~g} \mathrm{crude} \mathrm{kirrothricin}^{7)}$ yielded $912 \mathrm{mg}$ of a mixture of $1 \mathrm{a}$ and aureothin in the faster running fraction. Further purification was achieved by preparative TLC on silica gel with chloroform methanol $(9: 1)$ as eluant. Under UV light $(254 \mathrm{~nm})$ two separate zones could be seen. From the slower running zone $356 \mathrm{mg}$ (14 mg/liter culture broth) 1 a could be eluted. Crystallization was achieved by cooling down a solution of $1 \mathrm{a}$ in boiling chloroform over 2 days, yielding colorless crystals, $\mathrm{mp} 161^{\circ} \mathrm{C}$. $\mathrm{Rf} 0.36$ (TLC, ether). 1a is soluble in methanol, slightly soluble in chloroform or acetone, insoluble in pentane or water. IR (Fig. 1): 1633, 1617, 1582, $1572 \mathrm{~cm}^{-1}$. UV (MeOH): $\lambda_{\max }(\varepsilon) 295 \mathrm{sh}, 278 \mathrm{sh}$, 266 (14100), $224 \mathrm{~nm}$ (22200). UV (MeOH - HCl): $\lambda_{\max }(\varepsilon) 304$ (19900), 283 sh, 270 sh, $219 \mathrm{~nm}(23800)$. PMR and CMR see Table 1. Ms: $m / z$ (abund.) $=212\left(100 \%, \mathrm{M}^{+}, \mathrm{C}_{13} \mathrm{H}_{12} \mathrm{~N}_{2} \mathrm{O}\right), 197\left(36 \%, \mathrm{M}-\mathrm{CH}_{3}\right)$, $183\left(10 \%, \mathrm{M}-\mathrm{C}_{2} \mathrm{H}_{5}\right), 170(6 \%), 169(13 \%), 157(22 \%), 156(24 \%), 142(38 \%), 130(18 \%), 89(13 \%)$.

$\begin{array}{ll}\text { Anal. Calcd. for } \mathrm{C}_{13} \mathrm{H}_{12} \mathrm{~N}_{2} \mathrm{O}: & \text { C } 73.57, \mathrm{H} 5.70, \mathrm{~N} 13.2 \% \text {. } \\ \text { Found: } & \text { C } 73.34, \mathrm{H} 5.47, \mathrm{~N} 13.0 \% \text {. }\end{array}$

4-Bromo-2-ethyl-5-(3-indolyl)oxazole (1b)

a) A solution of $200 \mathrm{mg}(0.47 \mathrm{mmole})$ 2,4,4,6-tetrabromocyclohexa-2,5-dienone in $10 \mathrm{ml}$ chloroform was added to a solution of $100 \mathrm{mg}(0.47 \mathrm{mmole}) \mathbf{1 a}$ in $10 \mathrm{ml}$ chloroform. After 2 hours at $-10^{\circ} \mathrm{C}$ reaction was completed. After addition of $10 \mathrm{ml}$ water the $\mathrm{pH}$ was adjusted to 9 with $2 \mathrm{~N} \mathrm{NaOH}$ and the mixture was extracted with chloroform three times. The organic layer was dried over with sodium sulfate (anhydrous) and evaporated. The residue was purified by chromatography on silica gel with ether as current system. From the main zone (visible under UV light at $254 \mathrm{~nm}$ ) $\mathbf{1 b}$ was eluted and precipitated from chloroform with $n$-pentane yielding $90 \mathrm{mg}(52 \%)$ as colorless crystals, $\mathrm{mp} 158^{\circ} \mathrm{C}$. Rf 0.63 (TLC, ether). IR: 1626, 1607, $1566 \mathrm{~cm}^{-1}$. UV (MeOH): $\lambda_{\max }(\varepsilon) 322 \mathrm{sh}, 300 \mathrm{sh}, 288$ (13900), 272 (14600), $222 \mathrm{~nm}(31200)$. PMR $\left(\mathrm{CDCl}_{3}\right): \delta 1.42 / 2.92$ (t/q, $\left.J=7.5 \mathrm{~Hz}, 2-\mathrm{CH}_{2} \mathrm{CH}_{3}\right), 7.27\left(\mathrm{~m}, 5^{\prime}-\mathrm{H} /\right.$ $\left.6^{\prime}-\mathrm{H}\right), 7.45$ (m, 7'-H), 7.88 (d, $\left.J=2.7 \mathrm{~Hz}, 2^{\prime}-\mathrm{H}\right), 8.07$ (m, 4'-H), 8.47 (broad, NH). MS: $m / z$ (abund.) $=$ $292 / 290\left(98 \%, \mathrm{M}^{+\cdot}\right), 277 / 275\left(10 \%, \mathrm{M}-\mathrm{CH}_{3}\right), 263 / 261(2 \%, \mathrm{M}-29), 235 / 233(7 \%), 183(100 \%), 168$ 
$(8 \%), 156(18 \%), 144 / 142(34 \%), 128(13 \%), 116(20 \%) .89(20 \%), 56(27 \%)$.

Anal. Calcd. for $\mathrm{C}_{13} \mathrm{H}_{11} \mathrm{~N}_{2} \mathrm{OBr}$ : C 53.63, $\mathrm{H} 3.81, \mathrm{~N} 9.6, \mathrm{Br} 27.4 \%$.

Found:

C 53.84, H 3.84, N 9.7, $\mathrm{Br} 27.5 \%$.

b) A solution of $24 \mu \mathrm{l}(0.94 \mathrm{mmole})$ bromine in $5 \mathrm{ml}$ chloroform was added dropwise to a solution of $100 \mathrm{mg}(0.47 \mathrm{mmole}) \mathbf{1 a}$ in $10 \mathrm{ml}$ chloroform containing $50 \mathrm{mg}$ iron dust. The mixture was stirred at room temperature for 2 hours. After washing with water and evaporation of the dried organic layer a yellowish residue was obtained which was purified by preparative TLC on silica gel with ether as eluant. There are seen three main zones under UV light $(254 \mathrm{~nm})$, the slowest one contained unreacted 1a $(15 \mathrm{mg})$. The middle zone yielded $80 \mathrm{mg}(69 \%) \mathbf{1 b}$ which was identical with the compound described above.

4,2'-Dibromo-2-ethyl-5-(3-indolyl)oxazole (1c)

The quickest running zone from the forgoing experiment (b) yielded $20 \mathrm{mg}(14 \%) 1 \mathrm{c}$, which crystallized upon standing, $\mathrm{mp} 183^{\circ} \mathrm{C}$. Rf 0.71 (TLC, ether). IR: $1640,1617 \mathrm{w}, 1580 \mathrm{w}, 1560 \mathrm{~cm}^{-1}$. UV $(\mathrm{MeOH}): \lambda_{\max }(\varepsilon) 288 \mathrm{sh}, 280$ (10300), $272 \mathrm{sh}, 218 \mathrm{~nm}$ (27000). UV (MeOH - HCl): $\lambda_{\max }(\varepsilon) 288(9500)$, 280 (10300), 272 (10100), $218 \mathrm{~nm}$ (26600). UV (MeOH - NaOH): $\lambda_{\max }(\varepsilon) 305$ sh, 288 (9500), 279 (9600), $272 \mathrm{sh}, 230 \mathrm{sh} \mathrm{nm}$. PMR $\left(\mathrm{CDCl}_{3}\right): \delta 1.40 / 2.89\left(\mathrm{t} / \mathrm{q}, J=7.5 \mathrm{~Hz}, 2-\mathrm{CH}_{2} \mathrm{CH}_{3}\right), 7.23\left(\mathrm{~m}, 5^{\prime}-\mathrm{H} / 6^{\prime}-\mathrm{H}\right), 7.37$ $\left(\mathrm{m}, 7^{\prime}-\mathrm{H}\right), 7.57$ (m, 4'-H), 8.50 (s, broad, NH). $\quad$ MS: $m / z$ (abund.) $=372 / 370 / 368\left(100 \%, \mathrm{M}^{+\cdot}, \mathrm{C}_{13} \mathrm{H}_{10^{-}}\right.$ $\left.\mathrm{N}_{2} \mathrm{OBr}_{2}\right), 315 / 313 / 311(6 \%), 263 / 261(60 \%), 235 / 233(11 \%), 224 / 222 / 220(12 \%), 208 / 206(5 \%), 182$ $(28 \%)$.

Acknowledgement

We are grateful to Prof. H. ZäHNER (Tübingen) for providing us with crude extracts of Streptomyces cinnamomeus (strain Tü 89) and for testing the antibacterial activity. We thank Mr. R. MACHINEK for the measurement of the $200 \mathrm{MHz}$ PMR spectra, and the Deutsche Forschungsgemeinschaft and the Verband der Chemischen Industrie for financial support.

\section{References}

1) Umezawa, S.; T. Tsuchiya, K. Tatsuta, Y. Horiuchi, T. Usui, H. Umezawa, M. Hamada \& A. Yagi: A new antibiotic, dienomycin. I. Screening method, isolation and chemical studies. J. Antibiotics 23: $20 \sim 27,1970$

2) Umezawa, S.; T. Usui, H. Umezawa, T. Tsuchiya, T. Takeuchi \& M. Hamada: A new microbial metabolite, sphydrofuran. I. Isolation and the structure of a hydrolysis product. J. Antibiotics 24: 85 92, 1971

3) Tatsuta, K.; T. Tsuchiya, T. Someno, S. Umezawa, H. Umezawa \& H. Naganawa: Arglecin, a new microbial metabolite. Isolation and chemical structure. J. Antibiotics 24: 736 746, 1971

4) König, W. A.; H. Drautz \& H. ZäHner: Ketalin, ein Metabolit aus Streptomyces Tü 1668. Liebigs Ann. Chem. 1980: 1384 1391, 1980

5) Naegeli, H.-U. \& H. ZäHner: Stoffwechselprodukte von Mikroorganismen. 193. Ferrithiocin. Helv. Chim. Acta 63: 1400 1406, 1980

6) Drautz, H.; H. Zähner, E. Kupfer \& W. Keller-Schierlein： Stoffwechselprodukte von Mikroorganismen. 205. Isolierung und Struktur von Streptazolin. Helv. Chim. Acta 64: 1752 1765, 1981

7) Schranner, I.; H. Zähner, H.-U. Hoppe, I. Hummel \& A. ZeecK: Kirrothricin, a new member of the kirromycin-group. J. Antibiotics submitted to.

8) Zeeck, A.; H.-U. Hoppe \& I. Hummel: Die Konstitution des Kirrothricins. Tetrahedron Lett. 22: 2357 2360,1981

9) Schwartz, J. L.; M. Tishler, B. H. Arison, H. M. Shafer \& S. Ōmura： Identification of mycolutein and pulvomycin as aureothin and labilomycin respectively. J. Antibiotics 29: 236 241, 1976

10) Pataki, G.: Dünnschichtchromatographie in der Aminosäure- und Peptid-Chemie, p. 125, W. B. Gruyter, Berlin, 1966

11) Bell, R. A. \& J. K. SAunders: Correlation of the intramolecular nuclear Overhauser effect with internuclear distance. Can. J. Chem. 48: 1114 1122, 1970

12) Ernst, L. \& S. Kang: Carbon-13 n.m.r. spectroscopy of substituted indoles and tryptamines. J. Chem. 
Res. (M) 1981: 3019 3038, 1981

13) Caló, V.; F. Ciminale, L. Lopez \& P. E. Todesco: A selective bromination of aromatic amines. J. Chem. Soc. (C) $1971: 3652 \sim 3653,1971$

14) Koyama, Y.; K. Yokose \& L. J. Dolby: Isolation, characterization and synthesis of pimprinine, pimprinethine and pimprinaphine, metabolites of Streptoverticillium olivoreticuli. Agric. Biol. Chem. 45: 1285 1287, 1981

15) Yoshioka, T.; K. Mohri, Y. Oikawa \& O. Yonemitsu: Synthesis of oxazolylindole alkaloids from tryptamine and tryptophan by oxidation with 2,3-dichloro-5,6-dicyanobenzoquinone. J. Chem. Res. (S) 1981: $194 \sim 195,1981$

16) Joshi, B. S.; W. I. TAYlor, D. S. Bhate \& S. S. Karmarkar: The structure and synthesis of pimprinine. Tetrahedron 19: 1437 1439, 1963

17) Narasimhan, Jr., M. J. \& V. G. Ganla: Pimprinine in the treatment of hyperkinetic diseases. Hindustan Antibiot. Bull. 9: 138 141, 1967

18) Takeuchi, T.; K. Ogawa, H. Iinuma, H. Suda, K. Ukita, T. Nagatsu, M. Kato, H. Umezawa \& O. TANABE: Monoamine oxidase inhibitors isolated from fermented broth. J. Antibiotics 26: 162 167, 1973 